\title{
Shadow analysis: A method for measuring soil surface roughness
}

\author{
R. García Moreno , A. Saa Requejo , A.M. Tarquis Alonso , S. Barrington , M.C. Díaz \\ Dpto. de Edafología y Clinatología. E.TS. ingenieros Agrónonos, U.P.M. Ciudad Universitaria s.n. Madrid 28040, Spain \\ Dpto. de Matenática Aplicada. E.TS. Ingenieros Agrónomos, U.PM. Cindad Universitaria 5.n. MADRID 28040. Spain \\ Department of Bioresource Engineering, Macdonald Campus, McGill University, 21111 Lakeshore, Ste Anne de Bellevue (Québec), Canada H9X 3 vg
}

Keywords:

Micro-relief

Soil surface roughness

Pin meter

Ro0uglness indexes

Image analysis

\begin{abstract}
A B S T R ACT
Erosion potential and the effects of tillage can be evaluated from quantitative descriptions of soil surface roughness. The present study therefore aimed to fill the need for a reliable, low-cost and convenient method to measure that parameter. Based on the interpretation of micro-topographic shadows, this new procedure is primarily designed for use in the field after tillage. The principle underlying shadow analysis is the direct relationship between soil surface roughness and the shadows cast by soil structures under fixed sunlight conditions. The results obtained with this method were compared to the statistical indexes used to interpret field readings recorded by a pin meter. The tests were conducted on $4-\mathrm{m}^{2}$ sandy loam and sandy clay loam plots divided into $1-\mathrm{m}^{2}$ subplots tilled with three different tools: chisel, tiller and roller. The highly significant correlation between the statistical indexes and shadow analysis results obtained in the laboratory as well as in the field for all the soil-tool combinations proved that both variability (CV) and dispersion (SD) are accommodated by the new method. This procedure simplifies the interpretation of soil surface roughness and shortens the time involved in field operations by a factor ranging from 12 to 20 .
\end{abstract}

(c) 2008 Elsevier B.V. All rights reserved.

\section{Introduction}

Soil surface roughness (SSR) is defined as the standard deviation of elevation readings. After tillage, soil micro-topography exhibits randomly oriented tillage marks of different depths/heights, as well as clods (Allmaras et al., 1966; Zobeck and Onstad, 1987; Huang, 1998). Each type of tillage tool generates a characteristic oriented roughness pattern which is relatively easy to quantify using a simple geometric model. By contrast, quantifying the spatial distribution of randomly oriented soil surface roughness represents a challenge (Huang, 1998).

Quantitative descriptions of soil surface roughness furnish relevant information on erosion processes and the effects of anthropogenic activity, primarily tillage, on soil properties. Nonetheless, this parameter is not easy to quantify because of the scale of the measurements involved, ranging from centimetres to millimetres, and because they must be taken in the field with extremely sensitive instruments.

Huang (1998) defines the two steps involved in quantifying soil surface roughness to be the collection of surface data and the analysis of the respective dataset. While amply acknowledged, the effects of different processes on soil surface roughness have seldom been measured because the complexity and randomness involved are not readily expressed in mathematical terms (Römkens and Wang, 1987). Moreover, Huang (1998) states that field techniques are laborious and produce digitized soil topography data of low resolution limiting the results of analytical procedures.

At this time, the most common techniques for collecting soil surface data include: pin and profile meters (Burkwell et al., 1963; Podmore and Huggins, 1981; Römkens et al., 1986); stereophotography (Wagner, 1995; Zribi et al., 2000); laser scanners (Huang et al., 1988; Huang, 1998; Darboux and Huang, 2003) and the recently developed chain (Saleh, 1993; Merrill et al., 2001) and acoustic backscattering (Oelze et al., 2003) methods.

Pin meters are the devices most widely used for their simplicity. They consist in a single probe or a row of probes spaced at preestablished intervals and designed to slide up or down until the tip just touches the soil surface. Pin positions are recorded either electronically or photographically and subsequently digitized (Burkwell et al., 1963; Römkens et al., 1986; Wagner and Yiming, 1991). The chief disadvantage to this technique is its destructive impact on the soil surface.

Laser techniques, which are non-destructive (Huang et al., 1988), analyze the data by fractal interpretation. Laser technology generates very good laboratory results, but its field use is limited because sunlight and hidden forms or shadows interfere with the readings, while high temperatures affect the performance of the sensitive measuring devices involved (Pardini and Gallart, 1998; Pardini, 2003; Darboux and Huang, 2003).

The indexes and theories required to analyze data depend on the methodology used as well as the scale and magnitude of the database. The most widely used soil surface roughness measure is a statistical index known as random roughness (RR), defined as the standard error 
of soil heights estimated after adjusting for oriented roughness such as tillage marks or terrain grade (Allmaras et al., 1966; Currence and Lovely, 1970). Because RR assumes that soil surface is randomly rough and lacking in any spatial correlation, alternative statistical and geostatistical roughness indexes have been proposed to deal with the spatial component (Kamphorst et al., 2000; Vivas Miranda and Paz Gónzalez, 2002; Vidal Vázquez et al., 2005). Nonetheless, RR is still the most widely used index for analyzing soil surface roughness; while most of the existing single micro-relief indexes are based on variance either in height or in length as a spatial component, they fail to consider the two together (Hansen et al., 1999; Kamphorst et al., 2000).

A unified conceptual framework based on fractal parameters has recently been introduced to tackle the geometric complexity of soil surface roughness. Nonetheless, the variety of non-equivalent methods proposed for calculating fractal indices has curbed their use in describing soil micro-topography (Vidal Vázquez et al., 2005). Two types of fractal techniques can be defined: non-variational methods such as tortuosity (Bertuzzi et al., 1990) and the Richardson number (Gallart and Pardini, 1996; Pardini and Gallart, 1998), and variational methods, including the semi-variogram (Armstrong, 1986; Vivas Miranda, 2000; Vivas Miranda and Paz González, 2002), spectral analysis (Burg, 1967) and root mean square (RMS) or roughness length (Malinverno, 1990; Moreira and Da Silva, 1994; Vivas Miranda, 2000).

In light of the foregoing, the primary objective of the research reported in this paper was to develop new shadow analysis-based field methodology, drawing from prior studies, to obtain soil surface roughness data. Shadow analysis proved to meet field testing requirements, being simpler, more convenient and quicker than the techniques presently in use. Moreover, when this procedure was calibrated under different roughness conditions the data collected were found to be more readily analyzed and interpreted than the data gathered with existing techniques.

Shadow analysis was designed primarily for soils typical of central Spain, characterized by light, evenly distributed colours, a very low moisture content and a likewise low percentage of organic matter. The origin of most of the organic matter, in fact, is plant waste, essentially straw. In the summertime, moreover, very bright, sunny days prevail.

Inasmuch as the aim was to improve field techniques to measure soil surface roughness, the experimental design prioritized outdoor testing, but included a few laboratory trials to ascertain the feasibility of the method. Such trials were intended to relate the percentage of shadows to the statistical indexes used in the pin meter technique, comparing the two procedures under controlled conditions, i.e., height distribution and length.

\section{Materials and methods}

\subsection{Laboratory validation of shadow analysis}

Shadow analysis was developed for use in the field to compare and contrast the soil surface roughness (SSR) indexes developed for pin meters, as well as to lower the cost and inconvenience of field work.

Consequently, the method was first validated in the laboratory by correlating the percentage of shadows to the standard deviation (SD) and coefficient of variation (CV) values found for a series of controlled heights and SSR distributions.

The laboratory test consisted in measuring the shadows cast when artificial light was projected on a set of prisms with a $2 \times 2-\mathrm{cm}^{2}$ base and variable heights $(0.5,1,1.5$ or $2 \mathrm{~cm}$, Fig. 1$)$. Sets of three, six and nine prisms were positioned on an $18 \times 18-\mathrm{cm}^{2}$ panel to cast different shadow patterns. The surface roughness generated by such arrangements was compared to the shadows cast by a lamp simulating the daylight angle and conditions that prevail in the field. Photographs were taken with a Kodak DC 4800 digital camera from a position parallel to and at a distance of $1 \mathrm{~m}$ from the prisms; these conditions were kept constant throughout. The angle of the incident light was $45^{\circ}$, chosen to ensure the same resolution as in the field.

Since the relationship in a controlled situation between CV and SD on the one hand and the percentage of shadows on the other would be similar regardless of the geometric shape used, prisms - the simplest were chosen for this purpose.
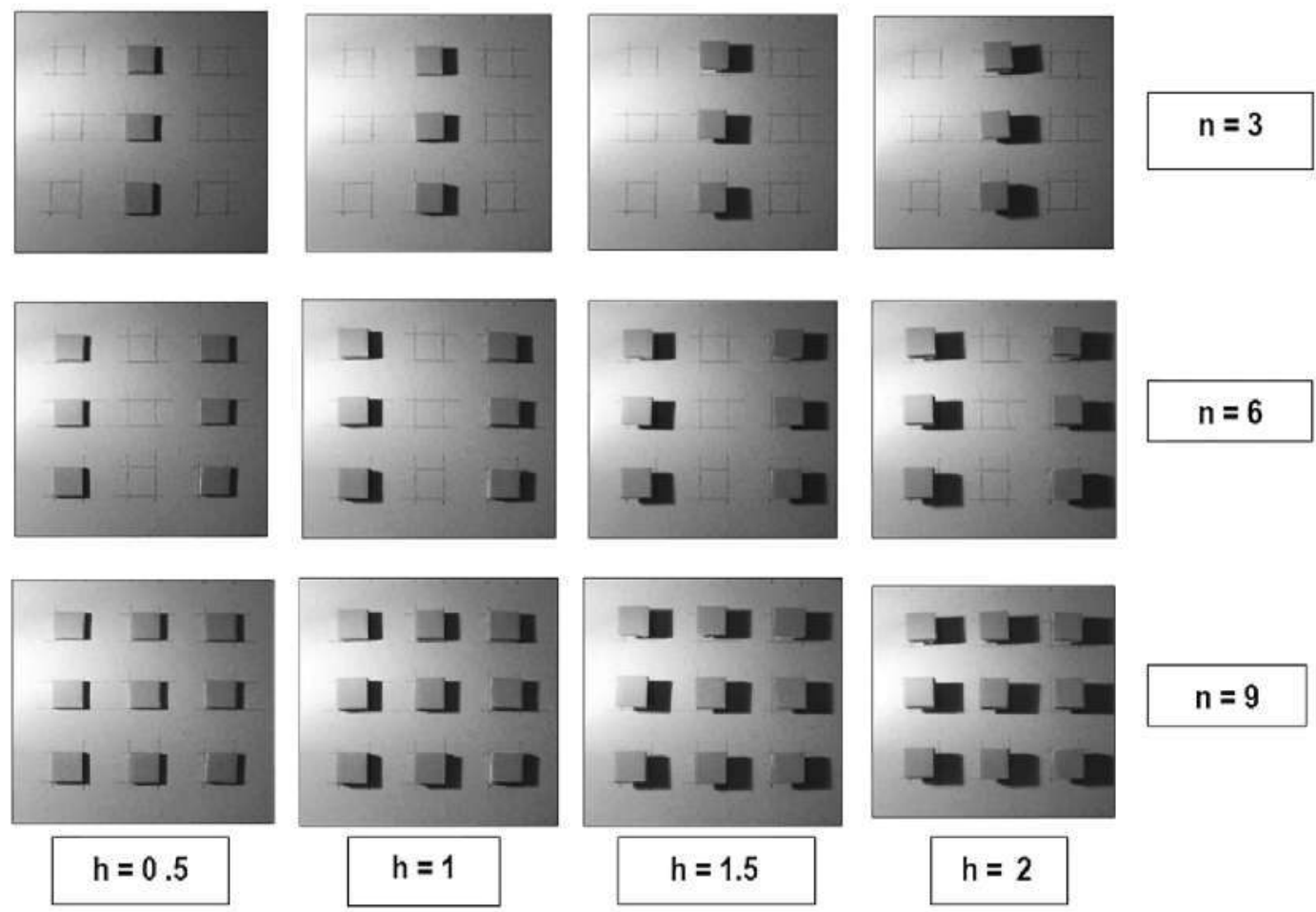

$n=9$

Fig. 1. Photographs showing prism heights and spatial patterns. 


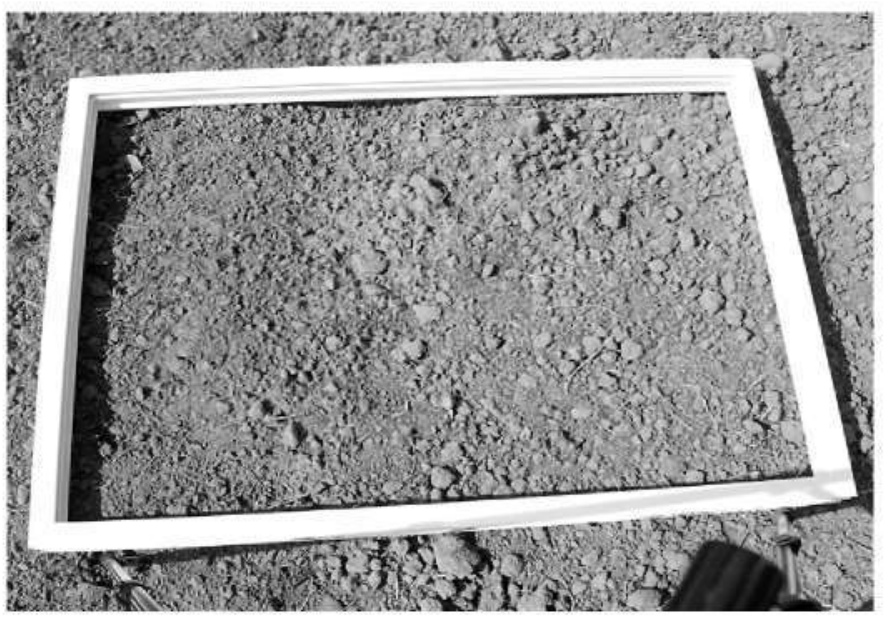

Fig. 2. Shadow analysis, field image (sandy clay loam soil tilled with a tiller).

The shadows projected by prisms of different heights and arranged in variable spatial patterns were analyzed on byte map histograms using Corel Draw Photo Paint (c) 1992-1996 Corel Corporation) software. The points representing shadows on the histogram were identified and converted into a black surface against a white background. The shadow index was then computed as the percentage of black pixels over the total number of pixels.

The percentage of shadows was compared to statistical indexes SD and CV (see Section 2.5 for further explanation) for 12 different spatial patterns, varying prism height $(h)$ and number $(n)$ as shown in Fig. 1.

The relationship between the statistical indexes and the percentage of shadows was subsequently obtained for each pattern, as discussed in the results.

After the laboratory findings were analyzed, the method was used in the field and the results of shadow analysis were compared to the SSR values recorded with a pin meter.

\subsection{Field shadow analysis}

In the field, the newly developed shadow analysis technique was used to measure the soil surface roughness index in an area of $4.0 \mathrm{~m}^{2}$, the same plot size as used for pin meter trials. Due to the soil surface

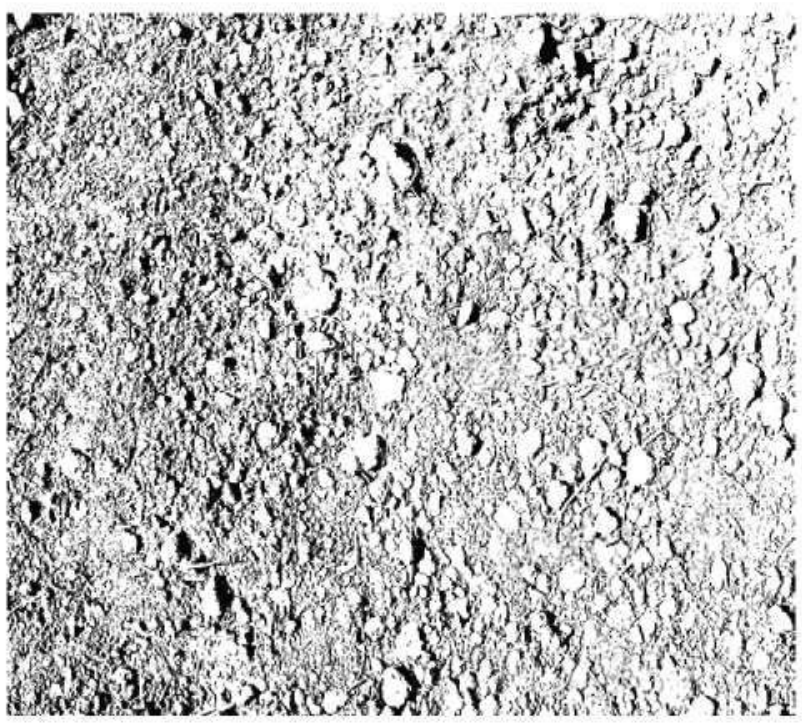

Fig. 4. Shadow analysis, black and white photograph of a sandy clay loam tilled with a tiller, Spanish National Research Council site at La Higueruela.

disturbance caused by pin meters, the shadow readings were taken first, for both shadow analysis and pin meter trials were conducted on the same plots. The datasets obtained with the two techniques were compared to determine the suitability of shadow analysis, based on the laboratory data.

Shadow analysis was developed on the assumption that shadows cast at a given angle in bright daylight are proportional to soil micro-relief. The images captured with the Kodak DC 4800 digital camera covered the same area as measured with the pin meter. All the photos were taken at a solar angle of $45^{\circ}$ to preclude any possibility of sunlight-induced differences. The test fields were all within a close enough distance to ensure that the angle of incident light was the same, and the photos were taken after tilling both types of soils with the three tillage tools. In addition, the angle was measured in each field before taking the pictures (Fig. 2).

The $4.0-\mathrm{m}^{2}$ plots used for each soil and tillage treatment were divided into four $1.0-\mathrm{m}^{2}$ subplots for the digitized photographs, which were subsequently reassembled. Duplicate images were taken to generate sufficient data to apply statistical analysis to detect the differences amongst soil type-tillage tool combinations.

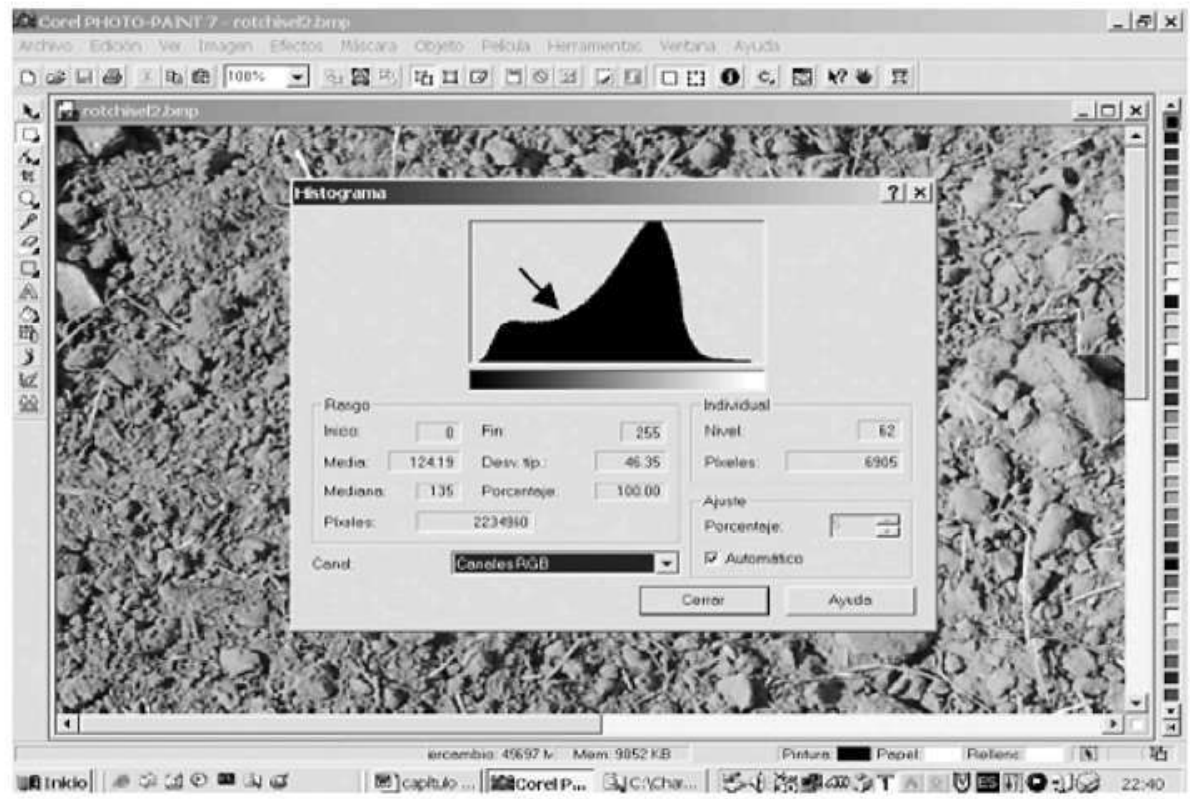

Fig. 3. Shadow analysis showing bimodal histogram of soil micro-relief in a sandy clay loam tilled with a tiller. 
The camera was set on a Silk tripod to photograph the entire $1.0-\mathrm{m}^{2}$ area in a single frame. This type of tripod was chosen because it provided the required distance. The camera lens was placed parallel to the soil surface at a height of $1.65 \mathrm{~m}$. The shadows cast by the soil micro-relief were analyzed with byte map histograms using Corel Draw Photo Paint (c) 1992-1996 Corel Corporation) software. After identification on the histogram the shaded points were converted into a black surface against a white background. The shadow index was then computed as the percentage of black over the total numbers of pixels (Figs. 3 and 4).

The focal angle and the distance from the lens to the ground were constant throughout to ensure that the resolution would be the same in all the pictures.
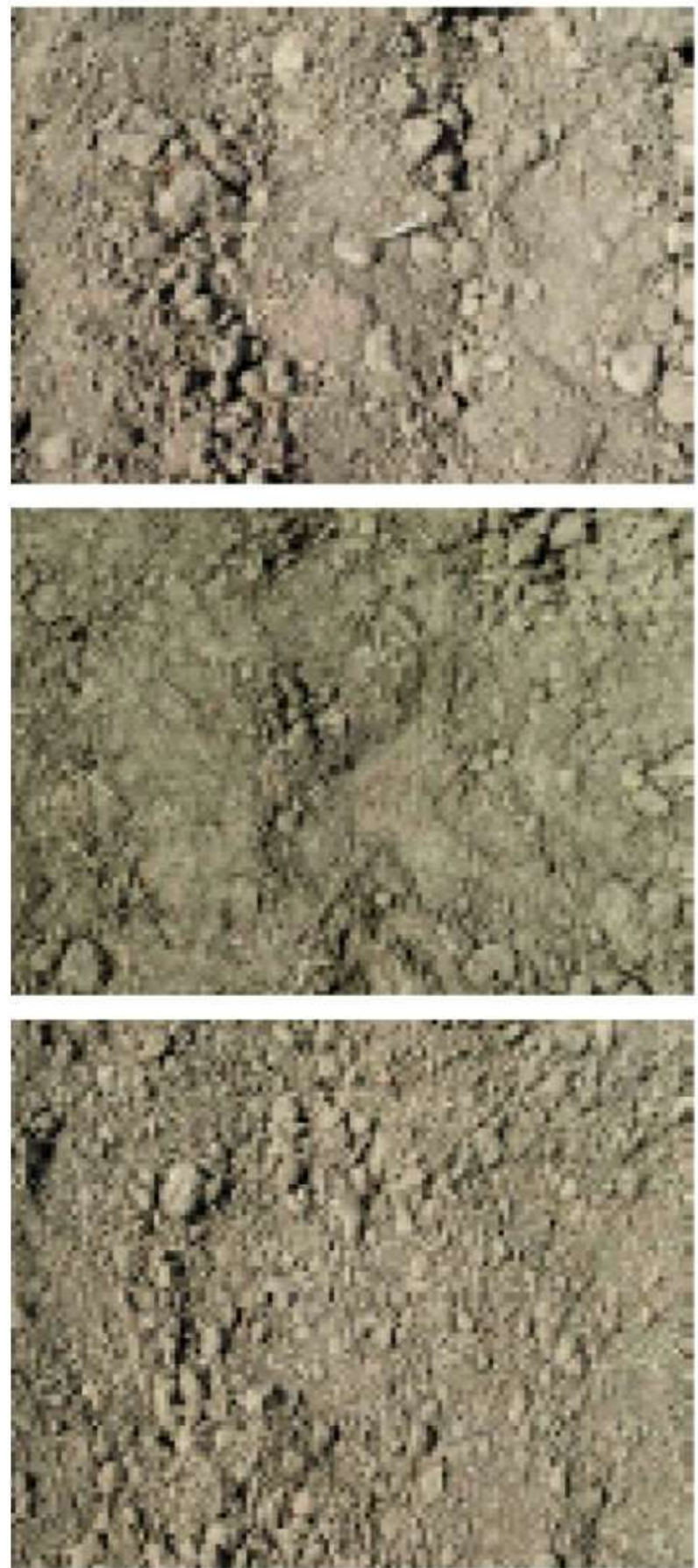

Fig. 5. Experimental sandy clay loam at the Spanish National Research Council's La Higueruela site, after tilling with a chisel, top, roller (middle) and tiller (bottom).
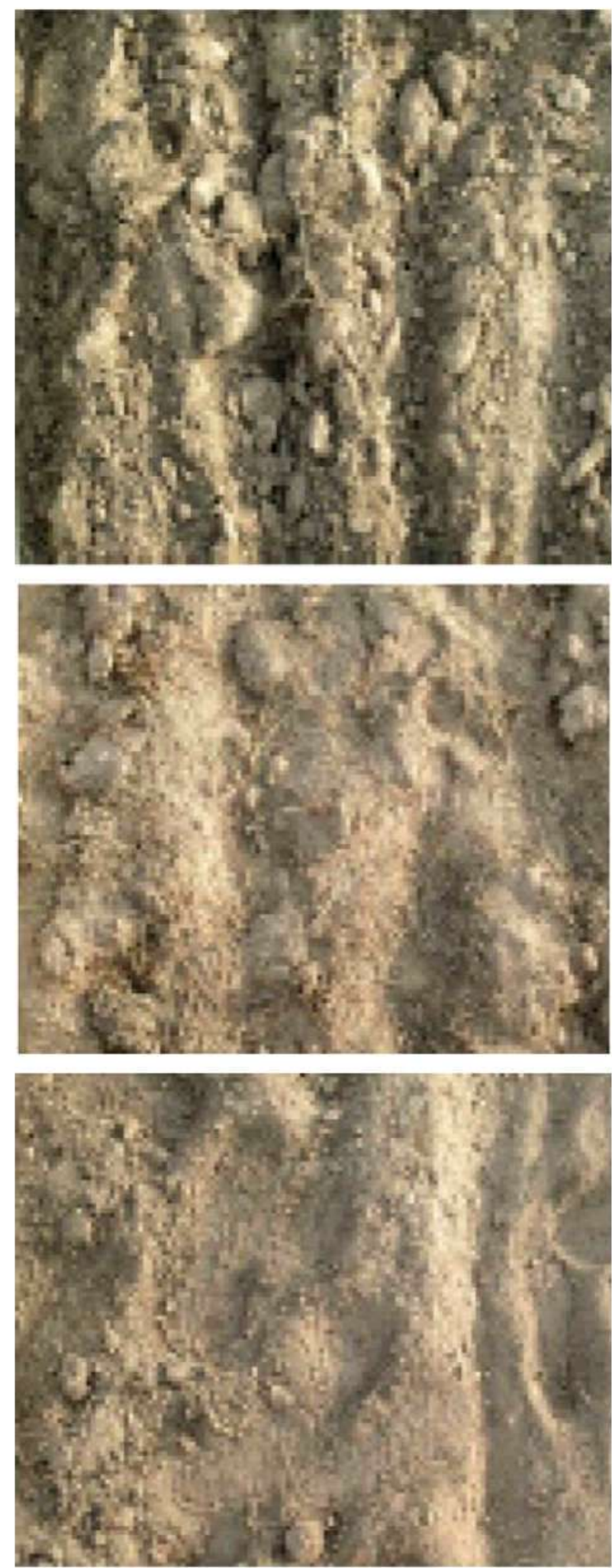

Fig. 6. Experimental sandy loam at the Spanish National Research Council's La Higueruela site, after tilling with a chisel, (top), roller (middle) and tiller (bottom).

\subsection{Experimental plots}

Each soil was tilled with the three tools most commonly used by farmers in central Spain, the chisel, tiller and roller. The soil surface roughness generated by each tillage operation was analyzed and the results compared. 
Table 1

Soil properties

\begin{tabular}{|c|c|c|c|c|c|c|c|}
\hline \multirow[t]{2}{*}{ Site } & \multirow[t]{2}{*}{$\begin{array}{l}\text { Conductivity } \\
\text { (dS/m) }\end{array}$} & \multirow{2}{*}{$\begin{array}{l}\text { Organic } \\
\text { matter } \\
(\%)\end{array}$} & \multirow[t]{2}{*}{$\mathrm{pH}$} & \multicolumn{3}{|c|}{$\begin{array}{l}\text { Textural analysis } \\
\text { (USDA calculator, \%) }\end{array}$} & \multirow{2}{*}{$\begin{array}{l}\text { USDA } \\
\text { texture } \\
\text { class }\end{array}$} \\
\hline & & & & Sand & Silt & Clay & \\
\hline La Higueruela 1 & $0.21(0.05)$ & $2.6(0.1)$ & $6.2(0.2)$ & $53(2)$ & $23(3)$ & $24(1)$ & $\begin{array}{l}\text { Sandy } \\
\text { clay loam }\end{array}$ \\
\hline La Higueruela 2 & $0.68(0.55)$ & $1.5(0.2)$ & $5.7(0.1)$ & $63(2)$ & $19(2)$ & $18(1)$ & $\begin{array}{l}\text { Sandy } \\
\text { loam }\end{array}$ \\
\hline
\end{tabular}

In parentheses: standard deviation for 12 samples.

The field data were gathered in 2005 , one of the driest seasons in Spain in the last 100 years, with no rainfall recorded in either the spring or the summer. While the average yearly rainfall in the region studied is $411 \mathrm{~mm}$, precipitation between 1 September 2004 and 31 August 2005 tumbled to $125 \mathrm{~mm}$ (Instituto Nacional de Meteorología, 2005).

The field experiments were conducted on two different soils in Spain's semi-arid central region, and more specifically at La Higueruela (Santa Olalla, province of Toledo), in the Spanish National Research Council's Experimental Station for Environmental Science. The plots were sufficiently close to ensure that the photos were taken after each tillage operation. The photographs in Figs. 5 and 6 show the experimental fields at La Higueruela after tilling with the three tools. The main soil characteristics, tested to Soil Science Society of America (1996) methodology, are given in Table 1.

With this methodology neither the possible effects of organic matter and moisture nor the impact of differences in soil colour were taken into consideration, for the soil in central Spain is characterized by a light, uniform colour, an organic matter content deriving mainly from straw cover, and a moisture content too low to affect soil colour, as can be seen in the pictures of the two soils in Figs. 5 and 6. In addition, under the very bright sunlight that characterizes the region studied, the rough surface profile of the soil, including any lumps or clods, casts shadows which are clearly darker and readily distinguishable from the much lighter coloured soil.

\subsection{Experimental pin meter}

The pin meter method was selected as a reference to for the field shadow analysis measurements in light of the reliability of this technique compared to laser technology where the results may be distorted by other sources of light (García Moreno, 2006). A pin meter was specifically designed for the present study on the basis of a review of the literature (Burkwell et al., 1963; Podmore and Huggins, 1981; Wagner and Yiming, 1991) and in keeping with the plot size $\left(1 \mathrm{~m}^{2}\right.$ ) (Fig. 7). The prototype consisted in a row of $35-\mathrm{cm}$ high pins, placed in a frame in which they could slide up or down to conform to surface irregularities. The pin heads were marked with a blue band to better visualize their respective positions when in contact with the soil. The device was designed to be moved horizontally without disturbing pin patterns. The total height of the instrument, which was made of aluminium, was $85 \mathrm{~cm}$. The pins were set against a white backing to ensure the visibility of the blue bands. With rows containing 50 pins spaced at $2-\mathrm{cm}$ intervals, each $x$-axis reading covered one full metre of ground. The $y$-axis readings were taken by sliding the instrument across the $1-\mathrm{m}^{2}$ plots. As the cells on the resulting grid measured $20 \times 20 \mathrm{~mm}$, a total of 2,500 readings were taken per square metre. An earlier study (García Moreno, 2006) showed this spacing to be sufficient to measure the surface roughness of the three types of soil.

Each corner of the instrument was marked with a red dot and software was developed that would detect these marks as the vertical and horizontal references for changes in row position (Fig. 7).
A Kodak DC 4800 digital camera set on a tripod was used to record pin positions as micro-topographic readings. The lens was focused on a point at the centre of the pin meter, i.e., at the average height of the red marks, to ensure the image would not be distorted. After comparing several models, a Silk tripod was found to be best suited to the $40-\mathrm{cm}$ camera height required. The 3.1-megapixel camera was fitted with a $\times 3(28-84-\mathrm{mm})$ optical zoom lens.

Since each plot, randomly chosen over a tilled area measuring $5 \times 10 \mathrm{~m}^{2}$, was divided into four $1-\mathrm{m}^{2}$ subplots, the same area used for the shadow method, the effects of each soil type and tillage tool were measured on four subplots. The data gathered were statistically analyzed to compare the effects of the different tool and soil types studied.

Readings were distinguished by the red marks at the corners of the instrument, which served as horizontal and vertical references, while the changes in the position of the blue bands on the pins reflected soil surface roughness.

The field procedure consisted in placing the pin meter on the surface of a $1.0-\mathrm{m}^{2}$ patch of soil and capturing the initial pin positions and all subsequent positions after each 20 -mm shift along the $y$-axis. The camera was initially placed at a distance of $2 \mathrm{~m}$ from the pin meter. The $x$-axis measurements were the positions of the 50 pins. The instrument was moved along the $y$-axis over two rails perforated at 20 - $\mathrm{mm}$ intervals, where the readings were taken. It was fitted with a hand brake to halt the process when soil was suspected to be on a slight grade.

Consequently, the area measured for each soil type was $2 \times 2 \mathrm{~m}^{2}$, with a resolution of $20 \times 20 \mathrm{~mm}^{2}$ along both the $x$-and $y$-axes. Since the experimental area comprised at least $40,000 \mathrm{~cm}^{2}$, a total of 10,000 point elevation measurements were taken on each field surface, with each point representing an area of $400 \mathrm{~mm}^{2}$. This arrangement generated sufficient data to calculate the soil surface roughness index and conduct Multi Fractal Analysis, MFA (Merel and Farres, 1998; Tarquis et al., 2003). All measurements were taken immediately after tillage with the different tools, to preclude interference from other factors.

\subsection{Statistical indexes}

A very relevant study by Kamphorst et al. (2000) was found in a review of the literature on indexes used to express soil surface roughness measured with pin meters.

Initially, random roughness (RR) (Allmaras et al., 1966; Currence and Lovely, 1970) was chosen, for it is the index most commonly used in all SSR studies. Since this index is defined to be the standard deviation for a line parallel to the direction of tillage, however, and the aim of the present study was to evaluate soil surface roughness for the

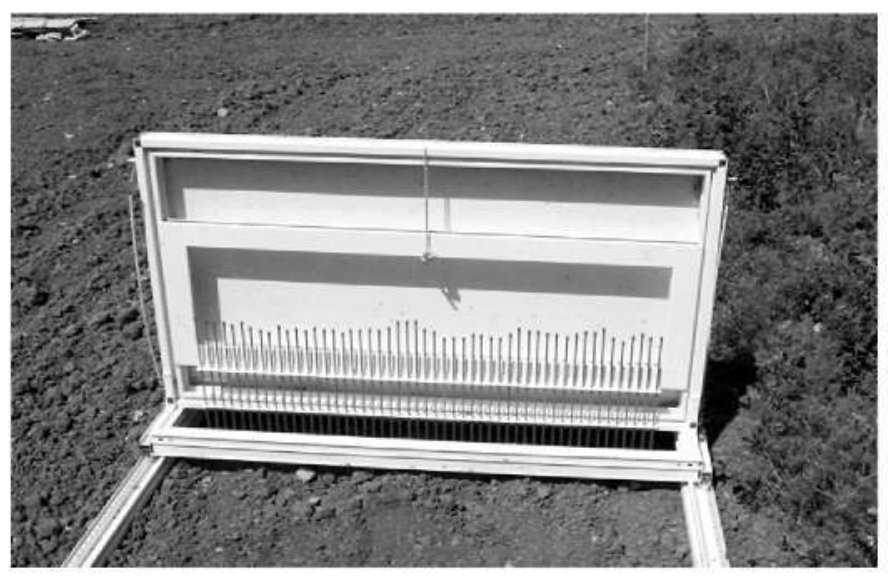

Fig. 7. Pin meter prototype, in the field. 
Table 2

Percentage of shadows and soil surface roughness indexes obtained for different prism heights and spatial patterns

\begin{tabular}{lllrrrll}
\hline$H$ & $c$ & Cut $^{\mathrm{a}}$ & \multicolumn{1}{c}{ pix- $n^{\text {b }}$} & pix-total & \% shadows & SD (mm) & CV (\%) \\
\hline 0.5 & 3 & 50 & 19,511 & $1,160,964$ & 1.7 & 0.1 & 5.2 \\
0.5 & 6 & 55 & 25,299 & 991,440 & 2.6 & 0.1 & 3.6 \\
0.5 & 9 & 60 & 32,615 & 928,896 & 3.5 & 0.2 & 2.9 \\
1 & 3 & 60 & 22,403 & 919,656 & 2.4 & 0.2 & 5.2 \\
1 & 6 & 60 & 46,749 & 973,880 & 4.8 & 0.3 & 3.6 \\
1 & 9 & 60 & 64,433 & 910,016 & 7.1 & 0.3 & 2.9 \\
1.5 & 3 & 60 & 38,608 & 978,870 & 3.9 & 0.3 & 5.2 \\
1.5 & 6 & 60 & 81,402 & $1,094,035$ & 7.4 & 0.4 & 3.6 \\
1.5 & 9 & 65 & 111,149 & $1,032,112$ & 10.8 & 0.5 & 2.9 \\
2 & 3 & 60 & 58,306 & $1,051,620$ & 5.5 & 0.4 & 5.2 \\
2 & 6 & 60 & 114,670 & $1,130,330$ & 10.1 & 0.5 & 3.6 \\
2 & 9 & 60 & 149,397 & $1,028,096$ & 14.5 & 0.6 & 2.9 \\
\hline a Histogram cut-off for shadow images. & & & & \\
b Shadow pixels. \\
c Total image pixels.
\end{tabular}

entire area, it is termed SD (standard deviation) hereunder. The SD index, which reflects random and oriented soil roughness both, is calculated as:

$\mathrm{SD}=\sqrt{\frac{1}{N-1} \sum_{i=1}^{N}\left[Z\left(x_{i}\right)-\bar{Z}\right]^{2}}$

where $x_{i}$ is point elevation measurement $i, Z(x)$ is the elevation at location $x, Z$ is the average value of $\operatorname{set}\left\{Z\left(x_{i}\right)\right\}$ and $N$ is the number of data points $(10,000$ in this study).

A second index, the coefficient of variation (CV), was used in addition to standard deviation:

$\mathrm{CV}=\frac{\mathrm{SD}}{\bar{Z}} * 100$.

While the SD field results were expressed in $\mathrm{cm}, \mathrm{CV}$ was expressed in percentage.

\subsection{Statistical design}

ANOVA was used to compare the effects of the various soil-tillage tool combinations. Since duplicate images were taken of each $1-\mathrm{m}^{2}$ subplot, the statistical design included 8 samples per combination.

When ANOVA indicated that a soil type-tillage tool combination had significant effects, the data were contrasted with Duncan's new multiple range test (Steel and Torrie, 1980).

Furthermore, a correlation between pairs of results was established to compare the statistical index findings to the percentage of shadows.

\section{Results and discussion}

\subsection{Relationship between laboratory index and shadow analysis findings}

The laboratory results for SD, CV and the percentage of shadows are summarized in Table 2 and their inter-relationships are shown in Fig. 8.

In the figure, the solid lines with squares plot percentage of shadows versus $\mathrm{SD}$, while the dashes with diamonds show $\mathrm{CV}$ versus SD.

Geometric forms other than prisms may be used, for in any event the same relationships would be found for any given spatial pattern. The aim of the laboratory trial was to establish the relationship between indexes $\mathrm{CV}$ and SD on the one hand and the percentage of shadows on the other, in an environment in which height and spatial pattern were controlled, as opposed to the completely random conditions prevailing in the field.

The experiment showed that the proportion of shadows was independent of geometry, and that the only differences were generated by the angle of incident light and spatial pattern. The angle of incident light was consequently controlled to ensure that the conditions were the same as prevailing in the field.

In all the cases studied, SD was observed to increase with the number and height of the prisms. The CV values were constant for the various spatial arrangements, regardless of prism height. This is logical, inasmuch as in CV, which is the standard deviation divided by mean height, the effect of height is precluded. CV was likewise found to decline with the number of prisms, for while the value of the mean remained unchanged, relative variability declined.

Hence, the relationship between SD and CV depended on the respective proportions of variability and dispersion in the sample. In the present case, the correlation between SD and CV was a nonsignificant 0.4 , with SD tending to rise as CV declined.

While the percentage of shadows was not constant for all the patterns with the same number of prisms, the value grew with the number and height of prisms. Consequently, it was positively related to both CV and SD.

Prismatic specimens were used because the shape is readily reproducible and the SD/CV versus percentage of shadows curve generated would have been the same with any other geometrically controlled form.

In addition to this analysis, each variable pair was correlated and the significance of the relationship found in each case. Specifically, the correlation coefficient for the percentage of shadows and SD was 0.96 at a significance level of $99.9 \%$, while it was 0.59 at a significance level of $95 \%$ for the percentage of shadows and CV. Multiple correlation, in turn, with a regression coefficient of 0.99 , explained $97 \%$ of the variance in the percentage of shadows in terms of SD and CV.

Further to these results, CV expresses soil surface roughness variability irrespective of height, whereas SD expresses total dispersion of the height values.

Since the percentage of shadows incorporates variability or CV and dispersion or SD both, and since in the laboratory results the percentage of shadows is more closely correlated to SD than $\mathrm{CV}$, the dispersion component seems to predominate when the angle of incident light is kept at a constant $45^{\circ}$, the distance between the camera lens and the object is constant and the height and spatial pattern of the geometric forms is uniform.

\subsection{Comparison of field results}

The SD and CV indexes found for the pin meter field measurements constituted the standard used to evaluate the effectiveness of the newly developed shadow analysis method for determining soil surface roughness. The results are given in Table 3.

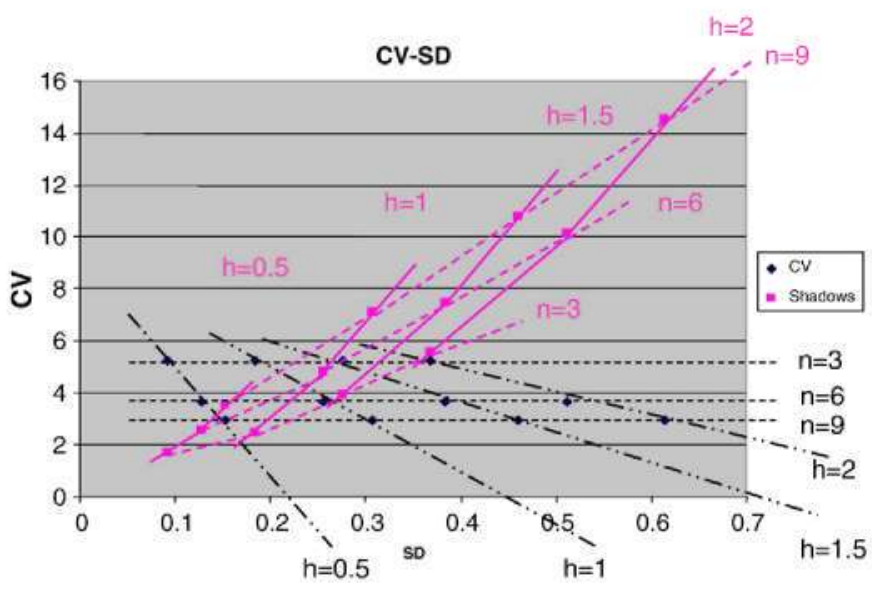

Fig. 8. Prism model. Relationships between SD (standard deviation), CV (coefficient of variation) and the percentage of shadows. 
Table 3

Percentage of shadows and surface rouglness indexes for tilled soils

\begin{tabular}{|c|c|c|c|c|}
\hline \multirow[t]{2}{*}{ Soil type } & \multirow[t]{2}{*}{ Tilling tool } & \multicolumn{2}{|c|}{$\begin{array}{l}\text { Statistical } \\
\text { indexes }\end{array}$} & \multirow[t]{2}{*}{$\begin{array}{l}\text { Percentage of } \\
\text { shadows }\end{array}$} \\
\hline & & $\mathrm{CV}$ & $\mathrm{SD}$ & \\
\hline \multirow[t]{3}{*}{ Sandy loam } & Chisel & 14.9 & 3.3 & $24.6(1.6)$ \\
\hline & Roller & 8.5 & 2.7 & $19.8(0.7)$ \\
\hline & Tiller & 7.8 & 1.8 & $18.0(1.6)$ \\
\hline \multirow[t]{3}{*}{ Clay sandy loam } & Chisel & $18.8 \mathrm{~d}$ & 3.5 & $37.3(8.4)$ \\
\hline & Roller & $24.7 d$ & 5.9 & $38.5(5.1)$ \\
\hline & Tiller & $13.8 \mathrm{a}$ & 3.0 & $32.9(2.2)$ \\
\hline
\end{tabular}

In parentheses: standard deviation.

The differences between soil type-tillage tool combinations were found to be significant (less than 95\% confidence level).

Where no significant difference was found, the values concerned are labelled with an "a" $(P \leq 0.05)$.

The indexes represent average soil roughness as evaluated for each soil and tillage tool combination studied.

Further to the results obtained for the soil type-tillage tool combinations, sandy clay loam exhibited greater soil surface roughness than sandy loam in the soil-weather system typical of central Spain. In these soils, which have a very low moisture content, the water retention capacity did not appear to be impacted by soil colour (Figs. 5 and 6). The pictures also show that the origin of the organic matter in the soil was plant waste, primarily straw, left on the surface. Since the colour of this waste was lighter than the colour of the soil, it did not alter the percentage of shadows, although it did contribute to soil surface roughness, generating the respective bimodal distribution.

The chisel, followed by the roller and tiller in that order, generated the most variable micro-relief in both soils. The chisel generated no specific pattern in sandy clay loam because the soil was too dry to be properly tilled. The results obtained using the two indexes were similar in all cases. As noted above and illustrated in Figs. 5 and 6, in the soils studied in conjunction with weather conditions, moisture content was found to have no impact on colour or therefore on the percentage of shadows pattern.

The analysis of variance performed to statistically compare the percentage of shadows results (Fig. 3) for the soil-tillage tool combinations showed that the mean values for the six groups differed significantly. A comparison of the results for tillage type only, however, showed that in sandy soil the chisel generated significantly greater surface roughness than the roller and tiller, while no significant differences were observed in the SSR occasioned by the three tillage tools in clay soil.

Moreover, tool by tool, the soil surface roughness value obtained for sandy clay loam was significantly higher than for sandy soil.

Generally speaking, the soil surface roughness findings for the different indexes were as expected for each soil type-tillage tool system, except for chisel-induced soil surface roughness in sandy clay loam soil.

An added advantage found for shadow analysis was the time needed to collect field data, which was from 12 to 20 times shorter than with the pin meter method, depending on whether pin meter positioning problems were encountered. More specifically, data collection with the pin meter technique took from 120 to $200 \mathrm{~min}$, compared to the $10 \mathrm{~min}$ needed to obtain the shadow analysis photographs.

\subsection{Relationship berween field index and field shadow analysis findings}

The soil surface roughness values for the soil-tool combinations, expressed as percentage of shadows and $C V$ and $S D$ indexes, are given in Table 3. The percentage of shadows results shown are the mean of the eight digital images analyzed per soil-tool combination; the figures in parentheses are the respective standard deviations.
A statistical analysis comparing the soil surface roughness index and percentage of shadows values yielded a correlation between SD and $C V$ that was $99.9 \%$ significant and a correlation coefficient of 0.91 for $\mathrm{CV}$ and the percentage of shadows at $98.8 \%$ significance. In other words, the shadow analysis results seem to be very closely correlated to the $\mathrm{CV}$ surface roughness index.

Moreover, while the correlation between the SD index and the percentage of shadows was 0.80 at $94 \%$ significance, the correlation between the field values for these two indexes was not statistically significant.

Unlike the laboratory findings, the field results for the percentage of shadows seemed to correlate more closely to CV than SD.

Given, as discussed above, that the percentage of shadows incorporates both variability (CV) and dispersion (SD), an analysis of the field results shows that:

1. The relationship between field $C V$ and $S D$ is an increasing function (by contrast to the decreasing function found for the laboratory prism model). This relationship would explain why, for the soils and tools used in the present study, soil surface roughness is the result of many low-relief structures of different heights as well as high relief structures with a much narrower range of heights. Contrary to the roughness identified in the laboratory, based on a study of pure geometric forms in orderly patterns, the surface roughness observed in the field after tilling is the result of both a large number of low-relief structures associated with the disturbance generated by the tilling tool and a few larger scale structures such as lumps or clods.

2. The percentage of shadows is more closely related to $\mathrm{CV}$ in the field and to SD in the laboratory prism model. Consequently, variability appears to prevail over dispersion in the field data analyzed. Conversely, in the geometric, neatly patterned laboratory structures, dispersion predominates in all the structures analyzed.

On the whole, the method proved to be valid for the semi-arid soils studied, whose moisture and organic matter content do not impact soil colour or the shadows associated with soil surface roughness. The combination of light coloured soils and bright midday sunlight guaranteed that the resulting histogram would be bimodal.

Image resolution, in turn, was consistent throughout, for both the angle of incident light and the distance between the camera lens and the soil were kept constant.

Histograms for irregularly coloured soils with a high moisture content photographed under dimmer light (on a cloudy day, for instance) would not be bimodal. Under such conditions, the method would have to be validated in keeping with soil colour and its relationship to the percentage of shadows generated by soil surface roughness for each soil type-tillage system.

\section{Conclusions}

The present study was conducted to develop a new method for measuring soil surface roughness that would be more reliable, reproducible and convenient to use in the field than existing procedures. Other features sought were low development and maintenance costs and adaptability to the climate and soil conditions prevailing in the arid and semi-arid regions of Spain, where moisture, organic content, soil colour and weather conditions ensure the generation of a bimodal histogram.

The data obtained with this new method, christened shadow analysis, was compared to the soil surface roughness results found with a pin meter, expressed as coefficient of variability, $\mathrm{CV}$, and standard deviation, SD. The field and laboratory results showed that shadow analysis yielded results significantly correlated to the pin meter findings, but with the advantage that the time invested in gathering field data was 12 to 20 times shorter. Image interpretation is likewise less time-consuming and the instruments needed are easier to use and more portable. 
A comparison of the laboratory and field values for $C V$ and $S D$, the two soil surface roughness indexes, to the shadow analysis results revealed the existence of a variability component associated with the coefficient of variation and a dispersion component associated with standard deviation.

The percentage of shadows proved to be more closely correlated to $\mathrm{CV}$ in the field and to SD in the laboratory prism model. Consequently, variability appeared to prevail over dispersion in the field data analyzed. This relationship would explain why, at least for the soils and tools used in the present study, soil surface roughness is the result of many low-relief structures of different heights as well as of high relief structures with a much narrower range of heights.

The difference between the laboratory and field findings can be explained by the lack of geometric forms and orderly spatial patterns in the latter. Further comparisons should be conducted with more random laboratory structures and more orderly and repetitive field patterns, for the laboratory conditions take no account of the effect of the lumps and clods found in the field.

The general conclusion to be drawn is that shadow analysis affords a very good measure of surface roughness in soils having properties that generate a bimodal histogram, namely uniform colour with respect to shadows, as a result of both intrinsic soil properties and weather conditions.

The method is applicable to light, uniformly coloured soils with a low, evenly distributed moisture and organic matter content, exposed to bright sunlight. These are the conditions that prevail in the semiarid regions of Spain.

The method would have to be validated prior to measuring surface roughness in soils with irregularly distributed moisture and dark and uneven organic matter and located in places characterized by dim daylight. Only dark or vivid and unevenly distributed colours interfere with roughness-induced shadows, generating a non-bimodal colour distribution. In light of the foregoing, the method described in this paper must be verified ad hoc under the conditions prevailing in each case. In short, the present study constitutes a first approach to the technique, which must be further researched under other field conditions.

\section{Acknowledgements}

The authors wish to thank Dr Carlos Lacasta, Director of the Spanish National Research Council's Experimental Centre for Environmental Science at La Higueruela Santa Olalla, Toledo, and his team, for their assistance with the field experiments.

\section{References}

Allmaras, R.R, Burwell, R.E., Larson, W.E., Holt, R.F., 1966. Total porosity and random roughness of the interrow zone as influenced by tillage. USDA Conserv, Res. Rep. 7 . $1-22$.

Armstrong, A.C., 1986. On the fractal dimensions of some transient soil properties. J. Soil Sci. 37. 641-652.

Bertuzzi, P., Raws, G. Couralt, D. 1990. Testing roughness indices to estimate soil surface changes due to simulated rainfall. Soil Tillage Res. 17, 87-99.

Burg, J., 1967. Maximum entropy spectral analysis. Proceedings of the 37 th Meeting Society of Exploration Geophysicist, Oklahoma City.

Burkwell, R.E., Allmaras, R.R., Amemiya, M., 1963. A field measurement of total porosity and surface microrrelief of soils. Soil Sci. Soc. Am. Proc. 27, 697-700.
Cumence, H.D. Lovely, W.G, 1970. The analysis of soil surface rouglness. Trans. ASAE 13 , $710-714$.

Darboux, F., Huang, C.-h., 2003. An instantaneous-profile laser scanner to measure soil surface microtopograplyy. Soil Sci. Soc. Am. J. 67, 92-99.

Gallart, F., Pardini, G. 1996. Perfilru: un programa para el anâlisis de perfiles microtopograficos mediante el estudio de la geometría fractal. Cuadernos Lab. Xeolóxico de Laxe, vol. 21, pp. 169-178 (in spanish).

García Moreno, R. (2006). Desarrollo de una metodología para la medición de la rugosidad del suelo. Ph. D. Dissertation, Polytechnic University of Madrid (UPM), pp. 120.

Hansen, B., Schjonning, P., Sibbesen, E., 1999. Roughness indices for estimation of depression storage capacity of tilled soil surfaces. Soil Tillage Res. 52, 103-111.

Huang, C.-h., 1998. Quantification of soil microtopograply and surface roughness Fractals in soil science. In: Baveye, Philippe, Parlange, Jean Yves, Stewart, Bobby A (Eds.), Advances in Soil Science. CRC.

Huang, C.-h., Whita, I., Thwaite, E.G., Bendeli, A., 1988. A non contact lasel system for measuring soil surface topography. Soil Sci. Soc. Am. J. 52, 350-355.

Instituto Nacional de Meteorologia, 2005. Ministerio de Medio Ambiente. http:/fwww. inm.es/web/izq/noticias/meteonotif2005.

Kamphorst, E.C., Jetten, V., Guérif, J., Pitkănen, J., Iversen, B.V., Douglas, J.T., Paz, A., 2000 Predicting depressional storage from soil surface roughness. 50 il $5 \mathrm{ci} .50 \mathrm{c}$. Am. J. 64 $1749-1758$.

Malinvemo, A., 1990. A single method to estimate the fractal dimension of self-affine series. Geoplyys. Res. Lett. 17 (11), 1953.

Merel, A.P., Farres, P.J., 1998. The monitoring of soil surface development using analytical photogrammetiy. Photogramm. Rec. 16 (92), 331-345.

Merrill, S.D., Huang, C.H., Zobeck, T.M., Tanaka, D.L., 2001. Use of the chain set for scalesensitive and erosion relevant measurement of soil surface roughness. In: Stott, D.E. Mohtar, R.H. Steinhardt, G.C. (Eds.), Sustaining the Global Farm, pp. 594-600.

Moreira, J.C., Da Silva, K.L, 1994. On the fractal dimension of profiles. J. Phys. A 27, $8079-8089$

Oelze, M.L., Sabatier, J.M., Raspect, R, 2003. Roughness measurements of soil surfaces by acoustic backscatter. Soil Sci. Soc. Am. J. 67, 241-250.

Pardini, G., 2003. Fractal scaling of surface roughness in artificially weathered smectiterich soil regoliths. Geoderma 117 (2203), 157-167.

Pardini, G., Gallart, FA., 1998. Combination of laser technology and fractals to andyze soil surface roughness. Eur. J. Soil Sti. 49, 197-202.

Podmore, T.H., Huggins, L.F., 1981. An automated profile meter for surface roughness measurements. Trans. ASAE 24:663-665, 669.

Römkens, M.J.M., Wang, J.Y., 1987. Soil roughness changes from rainfall. Trans. Am. Soc. Agric. Eng. 30 (1), 101-107 Catend, 17(4-5): 315-325.

Römkens, M.J.M., Singarayar, S., Gantzer, C.J., 1986. An automated non contact surface profile meter. Soil Tillage Res. 6, 193-202.

Saleh, A. 1993. Soil roughness measurement: chain method. J. Soil Water Colnserv, 48 $527-529$.

Soil Science Society of America, 1996. Methods of soil analysis, In: Sparks, D.L. (Ed.). Part 3 - Chemical Methods. 55SA Book Selies:5.

Steel, R.G.D., and Torrie, J.H., 1980. Principles and procedures of statistics: a biometrical approach. 2nd edition. Ed. McGraw-Hill Inc.

Tarquis, A.M., Giménez, D., Saa, A., Diaz, M.C., Gastó, J.M., 2003. Scaling and multiscaling of soil pore systems determined by image analysis. In: Pachepsky, Radcliffe, Selim (Eds.), Scaling Methods in Soil Physics. CRC Press. chap. 2.

Vidal Vâzquez, E., Vivas Miranda, J.G., Paz Gónzalez, A., 2005. Characterizing anisotropy and heterogeneity of soil surface microtopography using fractal models. Ecol. Model. 182, 337-353.

Vivas Miranda, J.G., 2000. Análisis fractal del microrrelieve del suelo (in Spanish). Ph. D. Disseltation, University of Coruña, P. 313.

Vivas Miranda, J.G., Paz Gonzâlez, A., 2002. Fractal models for the description of soil surface roughness. In: Rubio, J.L., Morgan, R.P.C., Asins, 5., Andreu, V. (Eds.) Proceedings of the third Intemational Congress Man and Soil at the Third Millennium, pp. 2099-2112. Geoforma Ediciones.

Wagner, W.S., 1995. mapping a three-dimensional soil surface with handheld $35 \mathrm{~mm}$ photography. Soil Tillage Res. 34, 187-197.

Wagner, LE., Yiming, Y., 1991. Digitization of profile meter photographs. Tralls. ASAE 34 (2), 412-416.

Zobeck, T.M., Onstad, CA., 1987. Tillage and rainfall effect on random roughness: a review Soil Tillage Res. 9 (1), 1-20.

Zribi, M., Ciarletti, V., Taconet O., Paillé, J., Boissard, P., 2000. Characterization of the soil structure and microwave backscattering based on numerical three-dimensional surface representation: analysis with a fractional Brownian model. Remote Sens. Environ. 72, 159-169. 